\title{
A case for revising the strength of the relationship between childhood asthma and atopy in the developing world
}

\author{
S Abbott, ${ }^{1}$ Cert Paed Pulm (SA); C Els, ${ }^{1}$ Cert Paed Pulm (SA); L Boonzaaier, ${ }^{1}$ MB ChB; P Becker, ${ }^{2}$ PhD; R J Green, ${ }^{1}$ PhD, DSc \\ ${ }^{1}$ Department of Paediatrics and Child Health, University of Pretoria and Steve Biko Academic Hospital, Pretoria, South Africa \\ ${ }^{2}$ Department of Biostatistics, Medical Research Council of South Africa, and Department of Paediatrics and Child Health, University of Pretoria, \\ South Africa
}

Corresponding author: S Abbott (salome.abbott@gmail.com)

Introduction. Asthma is the commonest chronic condition of children. Diagnosis remains difficult and many surrogate markers are used, such as documenting evidence of atopy.

Method. Two studies investigated the role of atopy in childhood asthma. The first documented the prevalence and nature of allergy sensitivities in a group of asthmatic children compared with non-asthmatic children in Pretoria, South Africa. The second enrolled a random sample of asthmatic children and their mothers attending the Children's Chest and Allergy Clinic at Steve Biko Academic Hospital, Pretoria. Children were classified as having atopic or non-atopic asthma. Mothers completed a questionnaire to reveal atopic features. Results. In the first study, only $45.0 \%$ of asthmatic children had a positive skin-prick test (SPT), as opposed to $16.2 \%$ of control children. This is a lower proportion than in many reported international studies. In the second study, 64 children with atopic asthma and 36 with non-atopic asthma were studied, along with their mothers. The proportion of children with atopic asthma did not differ for mothers with and without a positive SPT $(p=0.836)$, a history of asthma $(p=0.045)$ or symptoms suggestive of an allergic disease $(p=1.000)$, or who were considered to be allergic $(p=0.806)$. The odds ratio (OR) of a child having atopic asthma when he or she had a mother with a doctordiagnosed history of asthma was 4.76 , but the sensitivity was low (21.9\%).

Conclusion. The data demonstrate that fewer asthmatic children in South Africa are atopic than was previously thought. Also, all maternal allergic or asthmatic associations are poor predictors of childhood atopic asthma. Despite the increased risk of atopic asthma in a child of a mother who has a doctor diagnosis of asthma (OR 4.76; $p=0.045$ ), this is a poor predictor of atopic asthma (sensitivity $21.9 \%$ ).

S Afr Med J 2013;103(7):485-488. DOI:10.7196/SAMJ.6788

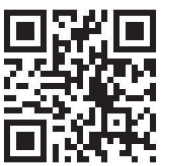

Asthma is one of the commonest childhood illnesses. Unfortunately in some cases the diagnosis remains difficult, particularly in the preschool wheezer. This leads to widespread under-diagnosis, which negatively affects the quality of life of asthmatic children.

In an attempt to provide insight into the wheezy infant, much research has been conducted in order to provide markers that could help predict and aid in the diagnosis of asthma in young individuals. Despite this, the epidemiology and disease expression of asthma and other allergic diseases remain poorly understood. In the Northern Hemisphere, the relationship between asthma and atopy has been clearly shown, ${ }^{[1-3]}$ with rates of atopic sensitisation being up to $59 \%{ }^{[4]}$ For this reason, the presence of atopy in children is often used as a surrogate marker to assist in making the diagnosis of asthma. ${ }^{[2]}$

In the developing world, and particularly in the South African context, the relationship between atopy and asthma may not be as clear. ${ }^{[5]}$ The role of the environment has been postulated to play a greater role than atopy in the aetiology and pathogenesis of asthma, ${ }^{[6-10]}$ as well as other allergic diseases. Some of these environmental factors include urbanisation, dietary changes, vitamin and micronutrient insufficiency, changes in microbial burden, and industrial pollution. It is possible that in the context of the developing world, these environmental factors may play a considerable role in the aetiology and expression of asthma and other allergic diseases. Although these environmental factors are independent of atopy in contributing towards the aetiology of asthma, they may occur concurrently in the same individual.

Since 2005, the role of atopy in childhood asthmatics attending the Steve Biko Academic Hospital Children's Chest and Allergy Clinic in Pretoria, South Africa, has been investigated in two important studies, in both of which a diagnosis of asthma was made by either of the following: ${ }^{[11]}$ (i) a history of respiratory symptoms that respond to bronchodilators; (ii) a history of respiratory symptoms that respond to inhaled or oral corticosteroids; and (iii) airway hyper-responsiveness, as demonstrated by reversible spirometry.

The research for the two studies was approved by the Research Ethics Committee of the Faculty of Health Sciences, University of Pretoria. Maternal consent and patient assent were obtained. Funding was provided by the University of Pretoria.

\section{The first study}

The first study documented the prevalence and nature of allergy sensitivities in a group of asthmatic children in Pretoria. In the context of this study, the following definitions are used: (i) atopy - positive skin-prick test (SPT) to common aero-allergens and/or foods, in the context of an allergic disease; ${ }^{[12]}$ and (ii) allergy - a hypersensitivity reaction initiated by immunological mechanisms.

\section{Objectives}

The primary aim of this study was to document the prevalence and nature of allergy sensitivities in a group of asthmatic children attending a tertiary hospital in Pretoria, South Africa, and to compare them with a group of matched non-atopic children.

\section{Methods}

A sample of 100 asthmatic children (67 black and 33 white) attending the Children's Chest and Allergy Clinic at Steve Biko Academic Hospital, Pretoria, were included after obtaining parental consent and patient 
assent. The children were randomly recruited as they arrived at the clinic. The age range was 2 - 239 months (mean 76.5 months, median 70.5 months). An age- and sex-matched control group of 50 non-asthmatic children was added. Tests using standard allergen extracts (Alk Abelló) with negative and positive controls were conducted on all children. SPTs were then conducted. The allergen extracts used were Bermuda grass, grass mix, tree mix, dog hair dander, cat hair dander, standardised house dust mite (Dermatophagoides pteronyssinus), Blattella germanica (cockroach), cow's milk, hen's egg, wheat, fish mix and peanut. Reactions were measured according to wheal size at 10 minutes, and a wheal $3 \mathrm{~mm}$ greater than the negative control was regarded as a positive reaction for inhalants and food allergens.

\section{Results}

Of the asthmatic children, $45.0 \%$ had a positive SPT. These allergens are shown in Fig. 1. The most common inhalant allergen in asthmatic children was Bermuda grass (22.0\%). Of the control children, $16.2 \%$ had a positive SPT. These allergens are shown in Fig. 2. The most common inhalant allergen in control children was house dust mite (6 children).

The rates of SPT positivity to food allergens were much lower than for the inhalant allergens. These allergens are shown in Fig. 3. Peanut allergy was seen in $9.0 \%$ of the patients. The second most common food allergy was egg white.

\section{The second study}

A second study was performed to further investigate the relationship between maternal atopy and asthma in the child. This has important implications, since atopy is relatively uncommon in our setting. Identification of atopy in relatives of asthmatic children may therefore be unhelpful in the diagnosis of childhood asthma, and practitioners would not need to waste time asking questions that do not provide information.

In the context of this study, the following definitions are used: (i) family history of allergy - family member with symptoms suggestive of an allergic disease or a known allergic disease, e.g. allergic rhinitis, asthma, food allergy; (ii) atopy - as above; (iii) atopic asthmatic - asthmatic with a positive SPT; (iv) non-atopic asthmatic - asthmatic with a negative SPT; and $(v)$ 'allergic' mother - presence of a positive SPT, or a history of allergic symptoms or disease.

\section{Objectives}

Our aim was to determine whether a maternal history of allergic disease or symptoms of such a disease and/or atopy is a useful predictor of the allergic basis of childhood asthma. This was performed by comparing: (i) the presence of atopy in mothers of atopic versus non-atopic asthmatic children; (ii) a history of asthma between mothers of atopic versus non-atopic asthmatic children; and (iii) the association between a maternal history of allergic symptoms in mothers of atopic versus non-atopic asthmatic children.

\section{Methods}

A sample of 100 children and their mothers attending the Children's Chest and Allergy Clinic at Steve Biko Academic Hospital, Pretoria, were enrolled after obtaining maternal and patient assent. The children were randomly recruited as they arrived at the clinic. SPT or ImmunoCAP test results of the children to common aero-allergens and foods were obtained from their hospital records.

Mothers completed a detailed questionnaire that included demographic details, birth history, occupation, habits, present environment, medical history, symptoms of atopy, and a history of symptoms suggestive of allergic diseases. These were subdivided into skin and upper and lower respiratory tract symptoms, such as allergic rhinitis, sinusitis, eczema and asthma, as well as any history of proven asthma.

SPTs were performed on the mothers as in the first study, using the same aero-allergen extracts.

\section{Statistical analysis}

The results were captured and the proportions compared using Fisher's exact test. Test characteristics were evaluated for sensitivity, specificity and predictive values using a standard two-by-two table.

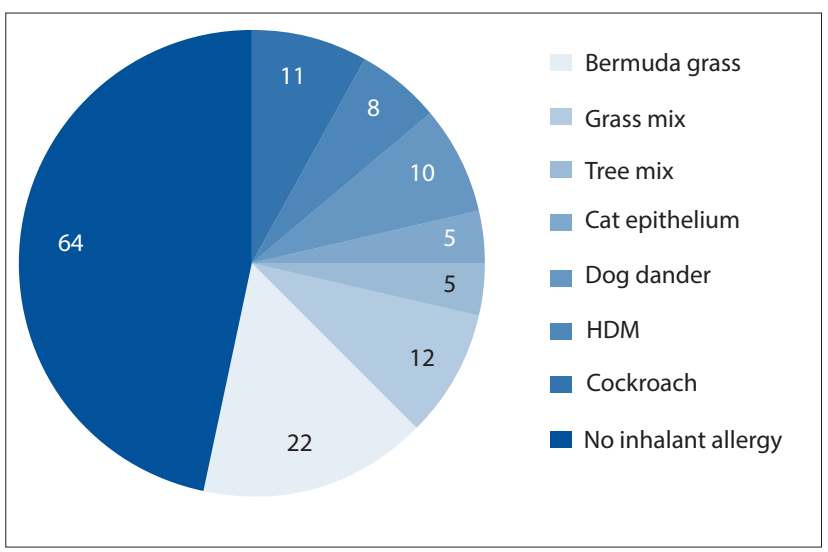

Fig. 1. Skin-prick test positivity for aero-allergens in asthmatic children in Pretoria $(\mathrm{N}=100)$. Some children had more than one positive test $(H D M=$ house dust mite).

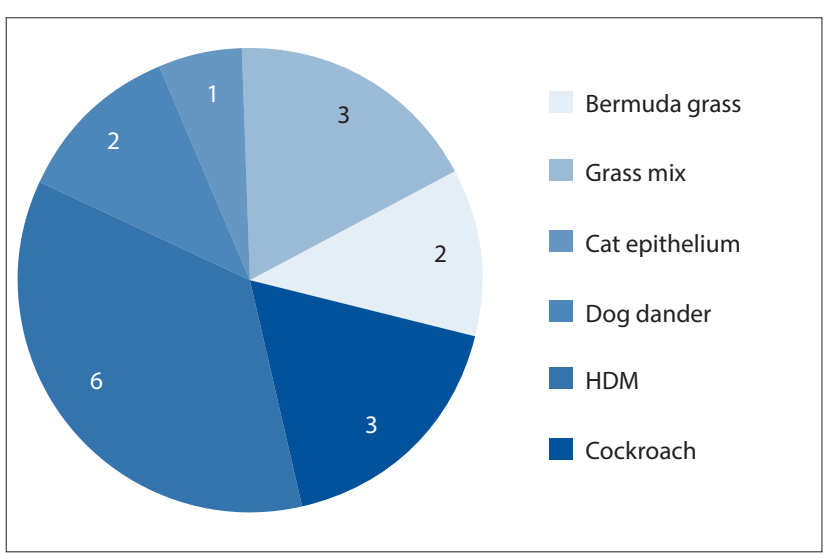

Fig. 2. Skin-prick test positivity in the control group, non-atopic children in Pretoria $(\mathrm{N}=50)(H D M=$ house dust mite).

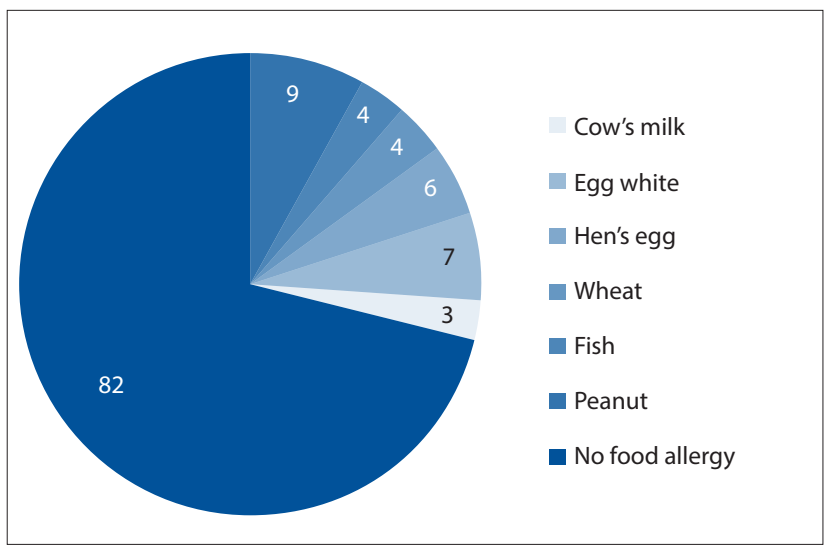

Fig. 3. Skin-prick test positivity to foods (number of positive tests). Some children had more than one positive test. 
Odds ratios (OR) were derived using logistic regression. The outcome of interest was asthmatic children with a positive SPT (used to distinguish between atopic and nonatopic asthma).

\section{Results}

One hundred children and their parents were enrolled. All the children were under 12 years old (age range 1 - 12 years, mean 6 years). Along with their mothers, 64 children with atopic asthma and 36 with non-atopic asthma were studied. The proportions of children with atopic asthma did not differ significantly for mothers with and without a positive SPT $(p=0.836 ; 0.625(30 / 48)$ v. $0.654(34 / 52))$ (Fig. 4), for mothers with and without symptoms suggestive of an allergic disease $(p=1.000 ; 0.643(45 / 70) \quad$ v. $0.633(19 / 30))$ (Fig. 4), for mothers who were considered to be allergic (presence of a positive SPT, or a history of allergic symptoms) or not allergic $(p=0.806 ; 0.649(50 / 77)$ v. $0.608(14 / 23))$ (Fig. 4), or for mothers with and without a history of doctor-diagnosed asthma ( $p=0.045$; $0.875(14 / 16)$ v. $0.595(50 / 84))$ (Fig. 5). The diagnostic variables (sensitivity, specificity and predictive values) are set out in Table 1.

The relative risk (OR) of a child having atopic asthma if he or she had a mother with or without the exposure variable is set out in Table 2. Despite the increased risk of atopic asthma in a child of a mother with a doctor diagnosis of asthma (OR 4.76; $p=0.045$ ), a mother with a doctor diagnosis of asthma is nevertheless a poor predictor of a child with atopic asthma (sensitivity $21.9 \%$ ).

\section{Discussion}

The data in the first study reveal that atopy is much less common in our childhood asthmatics than in the First World. Atopy was demonstrated in only $45.0 \%$ of asthmatic children, suggesting that using atopy as a diagnostic tool in our context may not be a perfect marker for asthma and that asthma must be associated with other, possibly environmental, exposures.

The second study demonstrates that all allergic or asthmatic associations in mothers are poor predictors of atopic asthma in their children; the descriptive statistics were low for all maternal factors. Only the association of maternal doctor-diagnosed asthma reached statistical significance $(p=0.045)$, but this may have limited clinical implications.

Despite the increased risk of atopic asthma in a child of a mother with a doctor diagnosis of asthma (OR 4.76; $p=0.045$ ), a mother with a doctor diagnosis of asthma is nevertheless a poor predictor of a child with atopic asthma (sensitivity $21.9 \%$ ). The falsenegative rate of this predictive test is high.

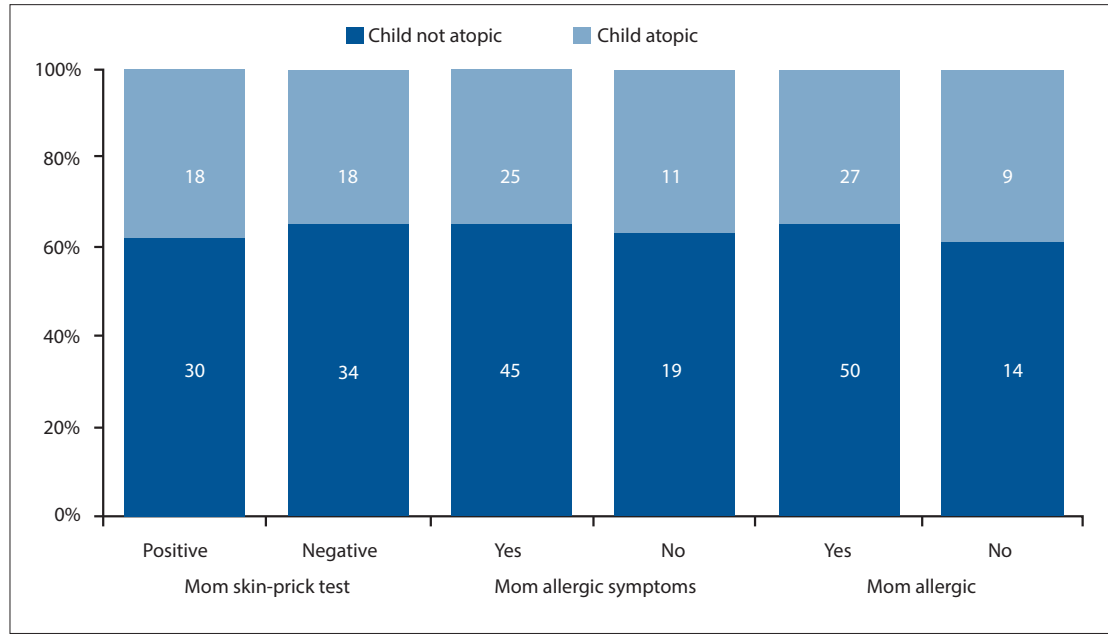

Fig. 4. Association between maternal allergy and childhood atopic asthma.

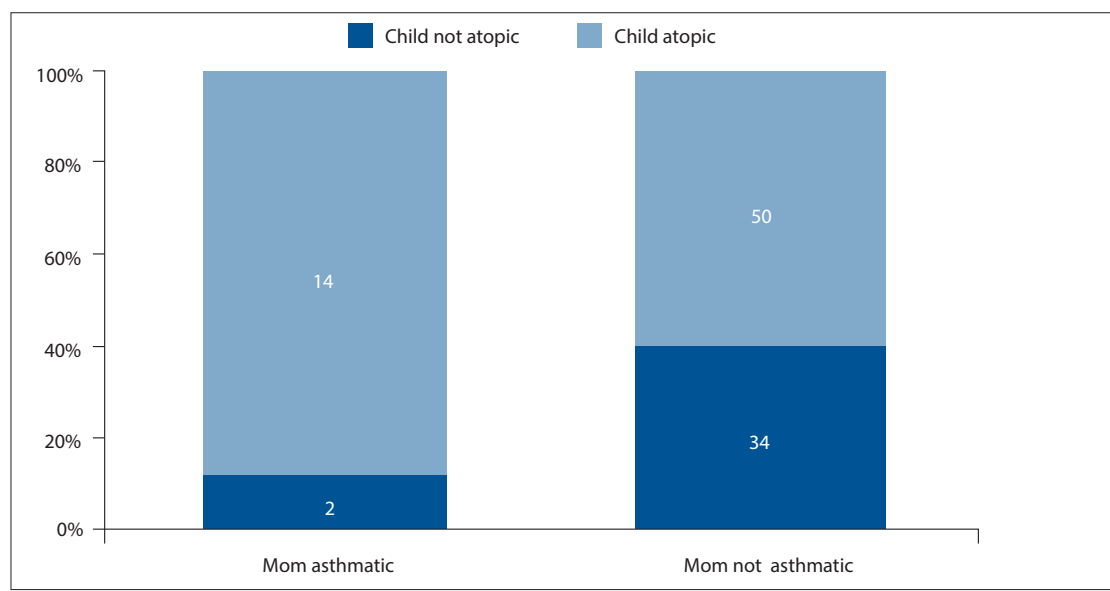

Fig. 5. Association between maternal asthma and childhood atopic asthma.

Table 1. Descriptive statistics for the relationship between maternal allergy or asthma and children with atopic asthma

\begin{tabular}{|c|c|c|c|c|}
\hline $\begin{array}{l}\text { Prevalence of } \\
\text { maternal: }\end{array}$ & $\begin{array}{l}\text { Doctor-diagnosed } \\
\text { asthma }\end{array}$ & $\begin{array}{l}\text { SPT } \\
\text { positive }\end{array}$ & $\begin{array}{l}\text { Allergic } \\
\text { symptoms }\end{array}$ & $\begin{array}{l}\text { Allergic symptoms } \\
\text { or SPT positive }\end{array}$ \\
\hline Sensitivity (\%) & 21.9 & 46.9 & 70.3 & 78.1 \\
\hline Specificity (\%) & 94.4 & 50 & 30.7 & 25 \\
\hline ROC area & 0.582 & 0.484 & 0.504 & 0.516 \\
\hline PPV (\%) & 87.5 & 62.5 & 64.3 & 64.9 \\
\hline NPV (\%) & 40.5 & 34.6 & 36.7 & 39.1 \\
\hline
\end{tabular}

Table 2. Odds ratio of a child having atopic asthma when having a mother with or without the exposure variable

\begin{tabular}{lllll}
\hline & $\begin{array}{l}\text { SPT } \\
\text { positive }\end{array}$ & $\begin{array}{l}\text { Doctor-diagnosed } \\
\text { asthma }\end{array}$ & $\begin{array}{l}\text { Allergic } \\
\text { symptoms }\end{array}$ & $\begin{array}{l}\text { Allergic symptoms } \\
\text { or SPT positive }\end{array}$ \\
\hline OR & 0.882 & 4.76 & 1.04 & 1.19 \\
$95 \%$ CI & $0.39-2.00$ & $1.02-22.30$ & $0.43-2.53$ & $0.46-3.11$ \\
SPT = skin-prick test; OR = odds ratio; CI = confidence interval. & &
\end{tabular}


These findings are important, because the literature suggests that the most reliable way to demonstrate the inherited tendency of asthma is to demonstrate a positive family history of atopy. ${ }^{[13]}$ This is why atopy is used as a surrogate marker to aid in the diagnosis of childhood asthma. In a cohort of 455 asthmatic black children at Baragwanath Hospital, Soweto, Johannesburg, South Africa, 70\% of patients had positive SPTs to allergens, ${ }^{[14]}$ compared with $45 \%$ in our first study. This may be due to racial differences between the two groups. In our cohort of patients, not only did a personal history of atopy occur less frequently than was previously thought, but a history of maternal atopy or allergic diseases was not a good predictor of childhood asthma.

It has previously been suggested that the reason for the poor association between a family history of allergic disease and childhood asthma may be lack of diagnosis of allergic diseases in family members ${ }^{[15]}$ because of under-reporting of symptoms by patients, or failure of doctors to recognise and diagnose allergic diseases. Parents should rather be asked about specific symptoms suggestive of asthma, allergic rhinitis and other allergic diseases. ${ }^{[15]}$ However, this cannot be the entire explanation for a poor family history, since mothers were specifically questioned concerning symptoms suggestive of allergic diseases. Adequate history taking is therefore not a simple solution to a complex problem. It is also possible that the allergens tested were incomplete and that some other allergen is important in association with asthma in our region. However, this seems unlikely.

It is possible that the relationship between asthma and atopy has been overestimated in the First World, ${ }^{[16]}$ or alternatively that this relationship, which clinicians rely on to aid in the diagnosis of childhood asthma in everyday practice, cannot be extrapolated to the developing world. Other risk factors for asthma in our setting may have been neglected.

Urbanisation has been shown to be linked to increased atopic sensitisation and bronchial hyper-responsiveness. ${ }^{[17]}$ Multiple factors have been implicated such as dietary changes, a more closed indoor climate, physical in-activity, electrification and medication. Other factors that deserve consideration are that an increased body mass index may lead to an increased prevalence of atopic disease, ${ }^{[18]}$ while prolonged breastfeeding has a protective effect in the development of allergic disease. ${ }^{[19]}$ Exposure to environmental tobacco smoke has an adverse effect on lung function in asthmatic children. ${ }^{[20]}$ All these variables are important to consider in children with non-atopic asthma.

\section{Conclusion}

These two studies demonstrate that atopy occurs in fewer asthmatic children in South Africa than in the developed world. Also, despite asthma disease expression having an inherited or genetic component, maternal atopy (positive SPT and an allergic disease process), a history of symptoms suggestive of allergic diseases and a history of maternal asthma were not good predictors of atopic asthma in children, raising questions about the uniform association between allergy and asthma, especially in Africa, and suggesting that asthma may be associated with other aetiological factors. Some environmental factors postulated are urbanisation, dietary changes, vitamin and micronutrient insufficiency, changes in microbial burden and industrial pollution.

These two studies have obvious limitations, including a small sample size and reliance on maternal history to differentiate allergic from non-allergic mothers. The mothers were also not examined, and lung function and reversibility tests were not performed. The results should therefore be confirmed by further, more detailed studies. However, the information obtained suggests that a new picture of childhood asthma in the developing world context, different to what was previously envisaged, is worthy of consideration. The diagnosis of asthma in young children is currently aided by a personal or family history of atopy or allergic diseases, but this may be less helpful in the South African setting than was previously thought. There are many unanswered questions that provide motivation for further studies to be conducted among different population groups, especially in South Africa, to shed more light on the complexity of the epidemiology and aetiology of childhood asthma in the developing world.

Declaration of conflict of interest. R J Green is a member of the Speakers Bureau for Abbott, Aspen GlaxoSmithKline, AstraZeneca, Boehringer Ingelheim, MSD, Nestlé, Nycomed, Pfizer, Pharmaplan and Roche, an Advisory Board Member of Abbott, Aspen GSK, AstraZeneca, Merck, MSD, Nycomed, Pfizer, Pharmaplan and Roche, has received funding from Abbott International, Aspen GSK and MSD, and is an executive member of the Allergy Society of Souith Africa, the National Asthma Education Programme and the South African Thoracic Society. The other authors declare no conflict of interest.

\section{References}

1. Martinez FD, Wright AL, Taussig LM, Holberg CJ, Halonen M, Morgan WJ. Asthma and wheezing in the first six years of life. The Group Health Medical Associates. N Engl J Med 1995;332(3):133-138. [http:// dx.doi.org/10.1056/NEJM199501193320301]

2. Castro-Rodriguez JA, Holberg CJ, Wright AL, Martinez FD. A clinical index to define risk of asthma in young children with recurrent wheezing. Am J Respir Crit Care Med 2000;162(4):1403-1406. [http:// dx.doi.org/10.1164/ajrccm.162.4.9912111]

3. Weinmayr G, Weland SK, Bjorksten B, et al. Atopic sensitization and the international variation of asthma symptom prevalence in children. Am J Respir Crit Care Med 2007;176(6):565-574. [http:// dx.doi.org/10.1164/rccm.200607-994OC]

4. Weinmayr G, Weland SK, Bjorksten B, et al. Atopic sensitization and the international variation of asthma symptom prevalence in children. Am J Respir Crit Care Med 2007;176(6):565.574. [http:// dx.doi.org/10.1164/rccm.200607-994OC]

5. Eysink PE, ter Riet G, Aalberse RC, et al. Accuracy of specific IgE in the prediction of asthma: Development of a scoring formula for general practice. Br J Gen Pract 2005;55(511):125-131.

6. Davis G, Luyt DK, Prescott R, Potter P. Housedust mites in Soweto. Curent Allergy and Clinical Davis G, Luyt DK, Prescott R, Potter P. Housedust mites in Soweto. Curent Allergy
Immunology 1994;7(1):16-17. [http://dx.doi.org/10.1111/j.1365-2222.1996.tb00071.x]

7. Wesley AG, Clyde JH, Wallace HL. Asthma in Durban children of three racial groups. S Afr Med J 1969:43(4):87-89.

8. Spieksma FThM, Zuiderme P, Leupen MJ. High altitude and house dust mites. BMJ 1971;1(5740):8284. [http://dx.doi.org/10.1136/bmj.1.5740.82]

9. Platts-Mills TAE, de Weck AL. Dust mite allergens and asthma - a world-wide problem. J Allergy Clin Immunol 1989;83:416-427.

10. Seaton A, Godden DJ, Brown K. Increase in asthma: A more toxic environment or a more susceptible population? Thorax 1998;49(2):171-174. [http://dx.doi.org/10.1136/thx.49.2.171]

1. South African Childhood Asthma Working Group. Guidelines for the management of chronic asthma in children. S Afr Med J 2009;99(12):898-912

12. Green RJ. Diagnostic testing in allergy. In: Green RJ, Motala C, Potter PC, eds. Handbook of Practical Allergy. 3rd ed. Cape Town: Oxford University Press, 2010:7-12.

13. Tariq SM, Matthews SM, Hakim EA, Stevens M, Arshad SH, Hide DW. The prevalence of and risk factors for atopy in early childhood: A whole population birth cohort study. J Allergy Clin Immunol 1998;101(5):587-593. [http://dx.doi.org/10.1016/S0091-6749(98)70164-2]

14. Luyt DK, Davis G, Dance M, Simmank K, Patel D. Clinical characteristics of black asthmatic children. S Afr $\operatorname{cod} 1$ 1995:85(10):999-1001.

15. Davis G, Green RJ, Hon H. Understanding the concept of 'family history' in black asthmatic children. South African Journal of Child Health 2007;1(1):14-18.

16. Pearce N, Pekkanen J, Beasley R. How much asthma is really attributable to atopy? Thorax 1999;54(3):268-272. [http://dx.doi.org/10.1136/thx.54.3.268]

17. Steinman HA, Donson H, Kawalski M, Toerien A, Potter PC. Bronchial hyper-responsiveness and atopy in urban, peri-urban and rural South African children. Pediatr Allergy Immunol 2003;14(5):383393. [http://dx.doi.org/10.1034/j.1399-3038.2003.00062.x]

18. Calvert J, Burney P. Effect of body mass on exercise-induced bronchospasm and atopy in African children. J Allergy Clin Immunol 2005;116(4):773-779. [http://dx.doi.org/10.1016/j.jaci.2005.05.025]

19. Obihara CC, Marais BJ, Gie RP, et al. The association of prolonged breastfeeding and allergic disease in poor urban children. Eur Resp J 2005;25(6):970-977. [http://dx.doi.org/10.1183/09031936.05.00116504] 20. Ehrlich R, Jordaan E, Du Toit D, et al. Household smoking and bronchial hyperresponsiveness in children with asthma. Journal of Asthma 2001;38(3):239-251. [http://dx.doi.org/10.1081//AS-100000111] 